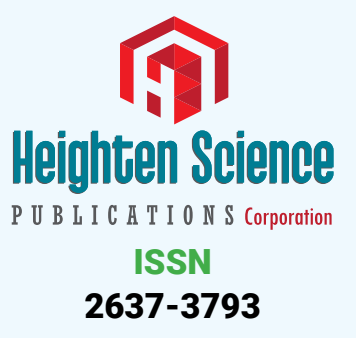

*Address for Correspondence: Stephen 0 Heard Department of Anesthesiology and Perioperative Medicine, University of Massachusetts Medical School and UMass Memorial Medical Center, Worcester MA 01655, USA, Email:

stephen.heard@umassmed.edu

Submitted: 02 February 2018

Approved: 05 February 2018

Published: 06 February 2018

Copyright: @ 2018 Christakis A, et al. This is an open access article distributed under the Creative Commons Attribution License, which permits unrestricted use, distribution, and reproduction in any medium, provided the original work is properly cited.

Keywords: Trauma; Phrenic nerve pslsy; Hemidiaphragmatic paralysis;

Pneumomediastinum; Anatomage; Clinical anatomy

Check for updates
Case Report

\section{Trauma to the neck: Manifestation of injuries outside the original zone of injury - A case report}

\author{
Alexander Christakis ${ }^{1}$, Brian Tashjian², Anne M Gilroy ${ }^{3}$ and \\ Stephen 0 Heard ${ }^{4 *}$ \\ 'Department of Pathology, Brigham and Women's Hospital Boston, MA 02115, USA \\ ${ }^{2}$ University of Massachusetts Medical School, Worcester MA 01655, USA \\ ${ }^{3}$ Department of Radiology, University of Massachusetts Medical School, Worcester MA 01655, USA \\ ${ }^{4}$ Department of Anesthesiology and Perioperative Medicine, University of Massachusetts \\ Medical School and UMass Memorial Medical Center, Worcester MA 01655, USA
}

\section{Summary}

A 53-year-old male presented to the Emergency Department (ED) with multisystem trauma and respiratory distress following a blunt-force injury to his anterior left neck. CT imaging showed extensive subcutaneous emphysema and pneumomediastinum. A chest $\mathrm{X}$-ray showed elevation of the left hemidiaphragm suggesting phrenic nerve injury which was confirmed by bedside ultrasonographic examination of the left hemidiaphragm. Flexible bronchoscopy demonstrated tracheal rupture. The patient was treated supportively and recovered without surgical treatment. Trauma-induced hemidiaphragmatic paralysis is rarely reported. This case represents a clinical scenario with demonstrable anatomic correlations, and a clinical reminder that phrenic nerve injury should be included in the differential diagnosis of respiratory distress in a trauma patient.

\section{Introduction}

Hemidiaphragmatic paralysis, also referred to as eventration in cases of congenital diaphragm malformations, is defined as "an abnormally high elevated position of one leaf of the intact diaphragm of as a result of paralysis, aplasia or atrophy of varying degrees of the muscle fibers" [1-3]. The most common causes of hemidiaphragmatic paralysis with phrenic nerve involvement have been reported to be malignant infiltration by bronchial carcinoma and direct injury [4]. The phrenic nerve can be compromised by both direct and indirect mechanisms of injury. Although unilateral diaphragmatic paralysis is relatively common, traumatic (indirect) causes are rarely reported and the incidence is unclear. Phrenic nerve injury related to neck trauma may lead to diaphragmatic paralysis and contribute to respiratory distress in the trauma patient. We report a case of non-penetrating trauma to the neck that resulted in tracheal rupture and phrenic nerve injury. We also use this opportunity to discuss the case from a clinical anatomy perspective including review of local anatomy, fascial planes in the neck, and course of phrenic nerve.

\section{Patient Information}

A 53-year-old male presented to the ED in a rigid cervical collar after a steel sign post fell from a truck at a construction site and landed across the anterior left side of his neck. The patient did not suffer a head injury and reported no loss of consciousness. He complained of severe neck pain, shortness of breath, and dysphagia. Physical exam demonstrated a respiratory rate of 11 breaths per minute and oxygen saturation $\left(\mathrm{SpO}_{2}\right)$ of $100 \%$ while breathing $100 \%$ oxygen via a nonrebreather mask. Crepitus was 
appreciated along the neck and anterior chest. Course breath sounds were present bilaterally. The remainder of the exam was otherwise unremarkable. His past medical history was significant for hypertension and nephrolithiasis.

\section{Diagnostic assessment}

Admission bloodwork was within normal limits. A CT angiogram of the neck with contrast showed severe extensive pneumomediastinum as well as air dissecting through the subcutaneous and soft tissues of the neck, noted to extend from the base of the skull superiorly to below the tracheal bifurcation inferiorly (Figure 1A,B). A large amount of air was observed dissecting the retropharyngeal space. A small focal defect was noted in the left anterolateral tracheal wall at the level of the thoracic inlet. Admission chest X-ray showed subcutaneous emphysema projecting over the lower neck and trapezius soft tissues with no displaced fractures and clear lungs; follow-up $\mathrm{X}$-ray showed elevation of the left hemidiaphragm (Figure 2A,B). Bedside ultrasound showed no movement of the diaphragm on the left side.

\section{Treatment}

Following initial stabilization in the Emergency Department, the patient was admitted to the Intensive Care Unit for observation given concern for airway edema and compromise. Flexible bronchoscopy under sedation was performed by Thoracic Surgery. A degloving-type injury involving the left lateral aspect of the trachea which covered $25-30 \%$ of the circumference of the cartilaginous trachea was found between the second and third tracheal ring. No surgery was recommended. An oral contrast study did not demonstrate an esophageal injury. The patient received supportive care which included supplemental oxygen by nasal cannula, treatments with aerosolized bronchodilators as needed, and wound care.

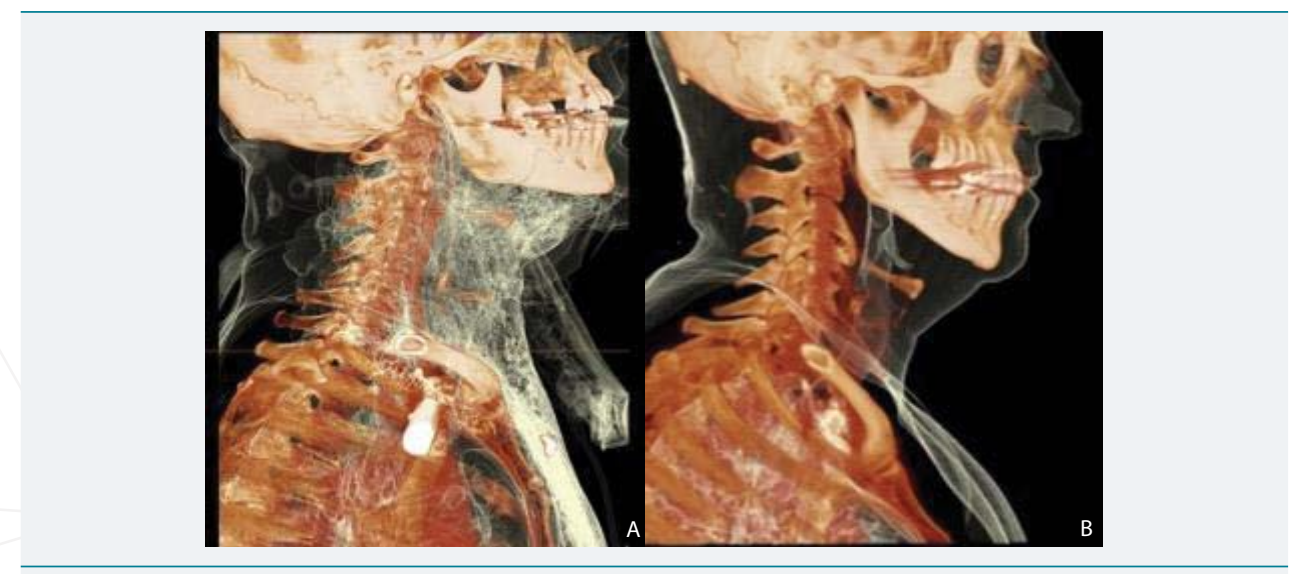

Figure 1: Sagittal 3-D view of the cervical area of $\mathbf{A}$ ) the described patient and B) a normal comparison, as illustrated on the Anatomage Table. Comparison reveals extensive subcutaneous emphysema.

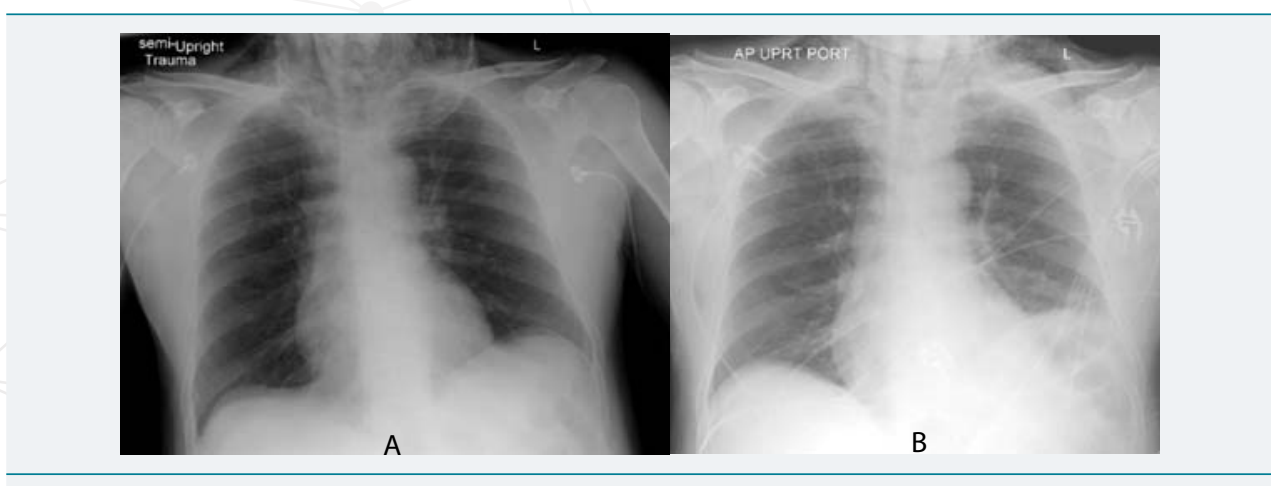

Figure 2: Chest X-ray of the current patient $\mathbf{A}$ ) in the ED, B) on day 2 of admission showing left hemidiaphragm elevation. 


\section{Outcome and follow-up}

The patient was transferred from the ICU to the acute care ward on the fifth day of admission. He developed a fever and was treated with amoxicillin. The patient was weaned off of supplemental oxygen, and discharged home two days later. Follow-up chest X-ray ten days after date of admission was within normal limits and without hemidiaphragm elevation (Figure 2C).

\section{Review of anatomy}

In this clinical case, the anterolateral portion of the neck was subjected to blunt force trauma sufficient to rupture the trachea, resulting in air dissecting into multiple musculofascial planes as well as into the retropharyngeal space (Figure $3 \mathrm{~A}, \mathrm{~B}$ ). The retropharyngeal space is the largest interfascial space in the neck and is technically a potential space between the visceral part of the prevertebral layer of deep cervical fascia and the superficial buccopharyngeal fascia, which extends inferiorly into the posterior mediastinum [5].

Subsequently, the left hemidiaphragm was found to be paralyzed, likely due to injury of the phrenic nerve during the original incident. The diaphragm has a central tendon with two muscular domes which are divided into three parts; the sternal part attaches to the xiphoid process, the costal part attaches to the internal surfaces of lower six ribs, and a lumbar part that attaches to the three superior lumbar vertebrae. The motor supply of the diaphragm is supplied solely by the left and right phrenic

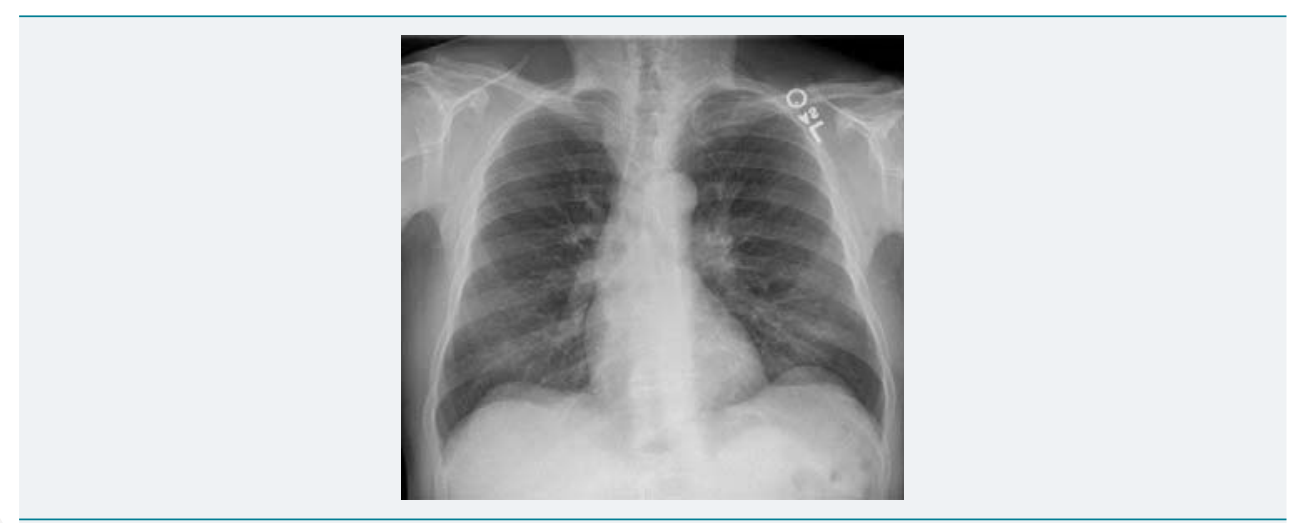

Figure 2C: 10 days after admission showing resolution.
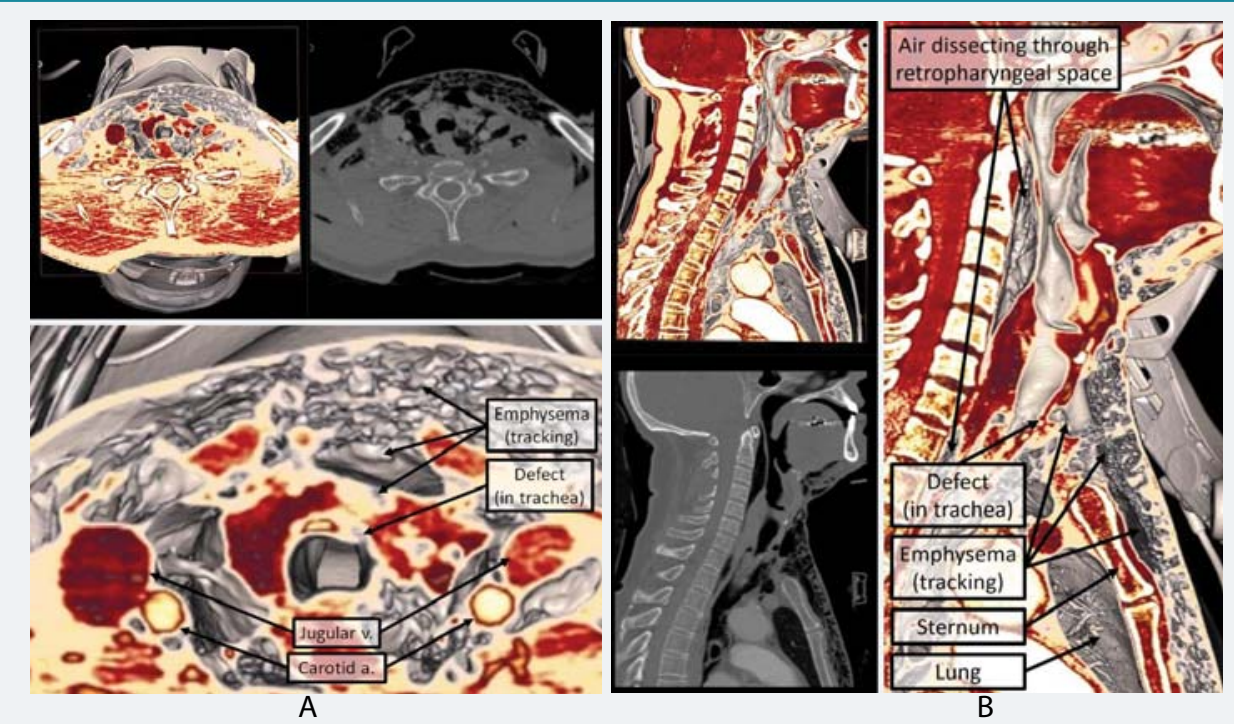

Figure 3: A) Axial and B) sagittal CT and Anatomage depictions of the multifascial involvement due to tracheal leak. 
nerves with each supplying its ipsilateral half. Sensory innervation is also mostly from the phrenic nerves, with some contribution to the peripheral diaphragm coming from the intercostal nerves [5].

The phrenic nerves arise from the anterior rami of the C3-C5 segments of the spinal cord. Each nerve receives a variable number of communicating fibers from the cervical sympathetic ganglia before forming at the supralateral border of the anterior scalene muscles. They descend on the anterior surface of the anterior scalene muscles beneath the prevertebral layer of deep cervical fascia and enter the thorax after passing between the subclavian artery and vein (Figure 4) [4,5].

The right phrenic nerve descends along the lateral side of the right brachiocephalic vein and superior vena cava. It passes anterior to the root of the lung and descends along the lateral border of the right atrium in the plane between the pericardium and mediastinal pleura. It continues along the right side of the inferior vena cava to the diaphragm, which it pierces near the caval opening. The left phrenic nerve passes along the left side of the aortic arch anterior to the left vagus nerve, and descends anterior to the root of the left lung. As on the right side, it passes between the pericardium and mediastinal pleura as it descends over the left atrium and left ventricle of the heart. Finally, it pierces the diaphragm on the left side. Most diaphragmatic branches from each phrenic nerve arise in the abdomen on the diaphragm's inferior (abdominal) surface [5].

\section{Discussion}

Injury to the phrenic nerve can be classified as direct or indirect. Direct injuries include transection, removal, or accidental or iatrogenic interventions. Iatrogenic interventions that have been reported to be associated with phrenic nerve injury

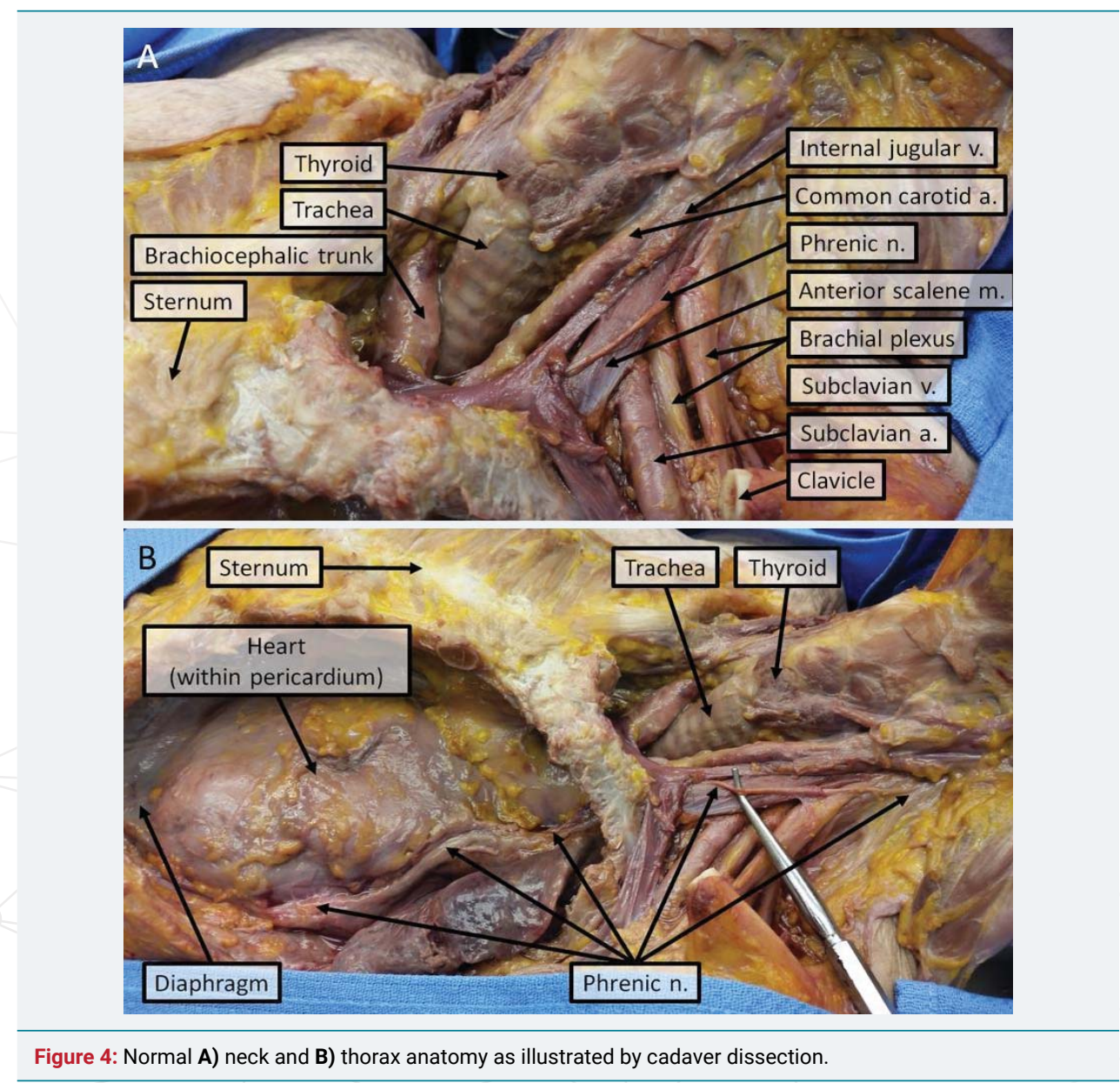


include radical neck dissection, lobectomy, cardiac bypass surgery, internal jugular or subclavian vein catheterization, radiofrequency ablation, and chiropractic manipulation [6-11]. Indirect nerve pathology results from crush or stretch mechanisms of injury to the neck or chest [3].

Mechanisms of traumatic phrenic nerve injury unrelated to surgery include penetrating trauma, blunt trauma, and traction injury. Review of the literature reveal case reports of phrenic nerve injury in trauma that describe mechanisms of injury including hyperextension of the neck, cervical neck flexion and rotation, blunt trauma to the anterior neck, crush injury of the thorax, and gunshot wound to the thorax and neck [2,3,12-15]. Specifically, unilateral diaphragmatic paralysis secondary to blunt trauma is rarely reported. The actual incidence is unclear but is thought to be more common than clinically recognized. The mechanism of injury in blunt trauma is most likely related to traction or stretching of the nerve [2,3]. In the current case, the patient suffered a blunt force injury across his thorax and anterior neck with a long, metal pipe. The impact was significant as the trachea was torn between the cartilaginous rings, likely due to shearing forces. The etiology of the phrenic nerve injury is not known for certain; it could be related to disruption of the anatomy in the neck given the local emphysema and edema or could be secondary to the blunt trauma with associated stretch or compression injury.

Clinical features vary and include shortness of breath, orthopnea, and respiratory distress. Physical exam findings show absent or diminished breath sounds, dullness to percussion, fremitus over the lower chest wall, and bowel sounds over the left lower lobe [3]. The diagnosis is typically suspected based on chest radiography or CT and can be further evaluated with fluoroscopy or ultrasound. The differential diagnosis of an elevated hemidiaphragm in the setting of blunt trauma includes diaphragmatic rupture and presents a diagnostic challenge since both can present with similar radiological findings $[12,13]$. Typically, surgical treatment is indicated only if persistent and symptomatic [2]. Generally, patients recover in 6-12 months, with some recovering much earlier with no further complications $[13,15]$.

This case represents a clinical scenario with demonstrable anatomic correlations. We use both virtual anatomy techniques and cadaveric dissection to illustrate the involved anatomy including the arrangement of fascial planes in the neck, retropharyngeal space, and the course of the phrenic nerve. The case also serves as a clinical reminder that phrenic nerve injury should be included in the differential diagnosis of respiratory distress in a trauma patient.

\section{References}

1. Bisgard JD. Congenital eventration of the diaphragm. J Thorac Surg. 1947; 16: 484-491. Ref.: https://goo.gl/Nve8fE

2. Dalshaug GB, Rothwell BC. Diaphragmatic paralysis following minor blunt trauma. J Trauma. 1999; 47: 413-415. Ref.: https://goo.gl/nTDUUW

3. Iverson LI, Mittal A, Dugan DJ, Samson PC. Injuries to the phrenic nerve resulting in diaphragmatic paralysis with special reference to stretch trauma. Am J Surg. 1976; 132: 263-269. Ref.: https://goo.gl/L9qMmC

4. Gibson GJ. Diaphragmatic paresis: pathophysiology, clinical features, and investigation. Thorax. 1989; 44: 960-970. Ref.: https://goo.gl/nKsjJv

5. Moore KL, Dalley AF, Agur AMR. Clinically oriented anatomy. 7th ed. Philadelphia: Wolters KluwerLippincott Williams \& Wilkins. 2014. Ref.: https://goo.gl/tftMAJ

6. Aguirre VJ, Sinha P, Zimmet A, Lee GA, Kwa L, Rosenfeldt F. Phrenic nerve injury during cardiac surgery: mechanisms, management and prevention. Heart, Lung \& Circulation. 2013; 22: 895-902. Ref.: https://goo.gl/tnS4FW

7. Harris $\mathrm{K}$, Maniatis G, Siddiqui $F$, Maniatis $T$. Phrenic nerve injury and diaphragmatic paralysis following pacemaker pulse generator replacement. Heart \& lung: J Critical Care. 2013; 42: 65-66. Ref.: https://goo.gl/Nxpvjk 
8. McCaul JA, Hislop WS. Transient hemi-diaphragmatic paralysis following neck surgery: report of a case and review of the literature. J R Coll Surg Edinb. 2001; 46: 186-188. Ref.: https://goo.gl/ojLgp6

9. Ostrowska $\mathrm{M}$, de Carvalho M. Prognosis of phrenic nerve injury following thoracic interventions: four new cases and a review. Clin Neurol Neurosurg. 2012; 114: 199-204. Ref.: https://goo.gl/89Y3h7

10. Schram DJ, Vosik W, Cantral D. Diaphragmatic paralysis following cervical chiropractic manipulation: case report and review. Chest. 2001; 119: 638-640. Ref.: https://goo.gl/vozTyf

11. Swallow EB, Dayer MJ, Oldfield WL, Moxham J, Polkey MI. Right hemi-diaphragm paralysis following cardiac radiofrequency ablation. Respiratory Medicine. 2006; 100: 1657-1659. Ref.: https://goo.gl/ipKj3G

12. Bell D, Siriwardena A. Phrenic nerve injury following blunt trauma. J Accident \& Emergency Medicine. 2000; 17: 419-420. Ref.: https://goo.gl/BViSYN

13. Hashim ND, Yunus MRM, Baki MM, Ami M. Laryngeal Trauma with Phrenic Nerve Injury: A Rare Association. Philipp J Otolaryngol Head Neck Surg. 2010; 25: 39-41. Ref.: https://goo.gl/o6aj15

14. Snyder RW, Kukora JS, Bothwell WN, Torres GR. Phrenic nerve injury following stretch trauma: case reports. J Trauma. 1994; 36: 734-736. Ref.: https://goo.gl/wbpJpA

15. Ulku R, Onat S, Balci A, Eren N. Phrenic nerve injury after blunt trauma. International surgery. 2005; 90: 93-95. 